\title{
Expressão de preocupação
}

\section{Expression of concern}

Editores chefe e associados dos Arquivos Brasileiros de Oftalmologia

Os Arquivos Brasileiros de Oftalmologia receberam uma carta direcionada ao editor acerca do artigo "Tracoma: estudo epidemiológico de escolares em Alagoas - Brasil" publicado neste periódico em 2009 (1). Os autores da carta, a qual está publicada neste fascículo, questionam aspectos éticos do artigo publicado. Dentre os questionamentos, inclui-se o uso indevido de dados de pesquisa, cujo planejamento e coleta foram realizados por pesquisadores e instituição não mencionados no artigo.

Os autores do artigo publicado foram contactados e expressaram sua resposta, cujo conteúdo encontra-se publicado neste fascículo. Os autores encaminharam aos Arquivos Brasileiros de Oftalmologia cópias digitalizadas da aprovação no Comitê de Ética em
Pesquisa da Universidade Federal de Alagoas e da autorização da Diretoria de Vigilância Epidemiológica da Secretaria de Estado da Saúde de Alagoas para uso dos dados.

Os Arquivos Brasileiros de Oftalmologia seguem as recomendações do Comitê Internacional de Editores de Periódicos Médicos $\left(\right.$ ICMJE) ${ }^{(2,3)}$. O ICMJE recomenda que a investigação seja realizada pela instituição dos autores do estudo. Se o resultado dessa investigação não produzir conclusões satisfatórias, o editor pode optar por conduzir investigação própria(4). Dessa forma, os Arquivos Brasileiros de Oftalmologia optaram por publicar a carta ao editor e a resposta dos autores neste fascículo, bem como informar a instituição dos autores do artigo sobre os questionamentos em relação ao trabalho. 


\section{REFERÊNCIAS}

1. Damasceno RW, Santos RR, Cavalcanti TR, Hida RY, Santos MJ, Santos AM, et al. Tracoma: estudo epidemiológico de escolares em Alagoas - Brasil. Arq Bras Oftalmol. 2009:72(3):355-9.

2. International Committee of Medical Journal Editors. Uniform Requirements for Manuscripts Submitted to Biomedical Journals: Writing and Editing for Biomedical Publications [Internet]. 2009 [cited 2011 Aug 9]; Available from: http://www.icmje.org
3. International Committee of Medical Journal Editors. Journals Following Requirements for Manuscripts Submitted to Biomedical Journals [Internet]. 2009 [cited 2011 Aug 9]; Available from: http://www.icmje.org/journals.html

4. International Committee of Medical Journal Editors. Uniform Requirements for Manuscripts Submitted to Biomedical Journals: Publishing and Editorial Issues Related to Publication in Biomedical Journals: Corrections, Retractions and "Expressions of Concern" [Internet]. 2009 [cited 2011 Aug 9]; Available from: http://www.icmje.org/ publishing_2corrections.html 